DOI: $10.17805 /$ trudy.2018.1.7

\title{
ИНКЛЮЗИВНАЯ КУЛЬТУРА В ОБРАЗОВАТЕЛЬНОЙ ОРГАНИЗАЦИИ
}

\author{
А. И. Полянский, В. Д. Мартиросян \\ Московский гуманитарный университет
}

\begin{abstract}
Аннотация: Инклюзивный подход предполагает понимание различных образовательных потребностей обучающихся и предоставление услуг в соответствии с этими потребностями через более полное участие в образовательном процессе, привлечение общественности и устранение сегрегации и дискриминации в образовании.
\end{abstract}

Ключевые слова: инклюзивная культура; социальная политика; культура обучения; эмпатия; нравственное поведение

\section{INCLUSIVE CULTURE IN THE EDUCATIONAL ORGANISATION}

\author{
A. I. Polyansky, V. D. Martirosyan \\ Moscow University for the Humanities
}

\begin{abstract}
The inclusive approach implies an understanding of various educational needs of students and the provision of services in accordance with these needs through fuller participation in the educational process, engaging the public and eliminating segregation and discrimination in education.
\end{abstract}

Keywords: inclusive culture; social policy; culture of learning; empathy; moral behaviour

В современном обществе актуальным и активно развивающимся направлением является инклюзия (от inclusion - включение). Складывается практика инклюзивного образования, приняты новые нормативные акты для развития общества и культуры в формате инклюзии. Инклюзивная культура образовательной организации - это новый запрос современности и легитимное требование к учреждениям и сервисам современного гетерогенного общества. Сотрудники Центра изучения инклюзивного образования в Бристоле Т. Бут и М. Эйнскоу разработали практическое пособие «Показатели инклюзии» (Бут, 2007: 124). Авторы рассуждают о трех взаимосвязанных аспектах, для развития образовательных учреждений современного общества: создание инклюзивной культуры, развитие инклюзивной политики и внедрение инклюзивной практики. Это три основных вектора реформирования не только современных образовательных учреждений, но и формирования нового 
мышления, развития общих инклюзивных ценностей объединяющих членов социума. Инклюзия задает новую парадигму системы образования, ориентирует на гуманистический характер самого образования, на развитие инклюзивной культуры и принятие ценностей социальной солидарности.

Согласно определениям многих европейских документов «социальная инклюзия есть процесс, включающий определенные усилия для достижения равных возможностей для всех, независимо от пола, возраста, социального статуса, образования, этнической принадлежности и т. д., с тем, чтобы обеспечить полноценное и активное участие во всех сферах жизни, включая гражданскую, социальную, экономическую и политическую активность и также участие в процессе принятия решений, а также процесс, с помощью которого общество борется с бедностью и социальной эксклюзией» (Creating an Inclusive ... , Электр. ресурс).

В рамках системы образования, инклюзивная культура становится особой философией, когда ценности инклюзии приняты и разделяются всеми участниками образовательного пространства. Инклюзия в школе - это часть общей школьной культуры, направленной на создание уникального микроклимата социальной солидарности, доверия, позволяющих избежать конфликтных ситуаций и создать особую атмосферу. Принцип уважения к человеческому разнообразию сегодня становится фундаментальной основой для создания культуры инклюзивного общества, в котором преодолевается дискриминация по признаку инвалидности, этничности и иным социально-культурным особенностям индивида.

Видимая часть инклюзивной культуры легко фиксируется, например, это инклюзивные классы в школе, где обучаются обычные дети и дети с ограниченными возможностями здоровья, это создание доступной среды, адаптированные образовательные программы, помогающие технические средства и технологии преподавания для разных категорий детей.

Скрытая часть инклюзивной культуры выражена в практиках невербальной коммуникации, в правилах поведения и социальных нормах, которым следуют педагоги, учащиеся и родители. Фиксировать латентную часть инклюзивной культуры сложно в силу глубинности и трудно анализируемых ценностно-смысловых основ взаимоотношений субъектов образовательного процесса. Н. М. Лебедева эту область культуры определяет, как «совокупность неосознаваемых положений, усвоенных процедур и способов поведения, которые были восприняты и вошли в привычку в такой степени, что люди не задумываются о них, это система представлений, норм, установок, ценностей и моделей поведения, которые являются общими для группы и являются условием устойчивости группы» (цит. по: Хухлаева, 2011: 146). Обучение можно считать инклюзивным лишь в том случае, если ребенок полностью включен в культуру образовательного учреждения. Для развития инклюзивной культуры в образовательном учреждении важны три вещи: культура обучения (правила поведения на занятиях, освоение знаний); культура коммуникации (знание и следование нормам поведения в образовательном учреждении, этике общения с педагогами и однокашниками); культура группы (владение языком доминирующей в учреждении группы детей, наличие условий для полноценного общения со сверстниками).

Задачей современной системы образования становится формирование особо- 
го образовательного пространства инклюзивной культуры, что предполагает принятие ценностей разнообразия и уважения к различиям, поощрение сотрудничества и внимание к достижениям каждого учащегося не зависимо от особенностей его развития или социального статуса. Дискриминирующие установки в образовательной среде, нежелание общаться и контактировать с «особыми» одноклассниками являются недопустимыми для современной школы и связаны в основном с дефицитом знаний о людях с ограниченными возможностями здоровья, страхом перед непохожими и иными людьми. Воспитательная и педагогическая деятельность в условиях современной школы должна быть направлена на морально-этическое развитие учащихся и персонала в духе принципов равноправия, гуманизма, принятия ценности каждого человека, не зависимо от особенностей его развития.

Рассматривая факторы развития нравственности в среде школьников, (Колокольцева, 2012: 47-48) выделяют три ключевых компонента: мотивационно-потребностный, ценностно-смысловой, поведенческо-волевой. Мотивационно-потребностный компонент фиксирует такие проявления в отношениях, как забота, взаимопомощь, этичное общение со сверстниками с особыми образовательными потребностями. Способность к сопереживанию, эмоциональное реагирование на проблемы и затруднения одноклассников, наполняют ценностно-смысловой компонент. Умения, навыки и привычки, проявляющиеся в социальных коммуникациях, устойчивость нравственного поведения и эмпатия в отношениях со сверстниками составляют поведенческо-волевой компонент, который является показателем уровня сформированности нравственного поведения. Для формирования инклюзивной культуры в образовательной среде необходимо использовать большой набор педагогических и психологических ресурсов, представленных в виде системы мер, воспитательных процедур, программ и правил взаимодействия, которые создают среду способствующую развитию и успеху каждого учащегося.

Сегодня стратегия развития инклюзивной организационной культуры актуальна не только для системы образования, но и для социальных и туристических сервисов, бизнес-структур, государственных и общественных организаций, городов в целом (Наберушкина, 2012: 123). Согласно действующему законодательству об образовании, вузы, школы и детские сады являются образовательными организациями, которые должны быть доступны для всех категорий детей и подростков. Инклюзивная культура образовательных учреждениях в основном формируется путем создания информационных и иных материалов, доступных всем (адаптированные для слабовидящих вебсайты, понятные информационные буклеты и т. д.).

Ключевым в создании инклюзивной культуры является формирование установок на принятие и понимание разнообразия и равноправия. Сегодня для успешной инклюзии в ряде образовательных организаций используются следующие методические приемы: включение в расписание тренингов и занятий для понимания инвалидности; информирование учащихся о нормальности жизни людей с инвалидностью; разработка проектов и подходов для успешного совместного обучения и взаимопомощи учащихся; обучение использованию корректного языка и слов об инвалидности. В образовательных организациях для младших возрастных групп для понимания культуры инклюзии и принятия человеческого разнообразия 
логично использовать сказки, песни, спектакли, ролевые игры, рисование, мультфильмы.

На разных этапах онтогенетического развития индивида, используемые приемы должны учитывать возрастную специфику, например в вузе для понимания инвалидности и причин дискриминации можно использовать метод просмотра фильмов, показанных в рамках кинофестиваля «Кино без барьеров». Дошкольный возраст оптимален для формирования таких личностных качеств, как эмпатия, в этом возрасте проявляется интерес к социальным и культурным различиям, происходит интенсивное психическое развитие детей, развивается саморегуляция, становится ценным общение и сотрудничество с другими людьми, появляется потребность в признании и уважении, формируется готовность к взаимопомощи и сочувствию (Сиротюк, 2014: 49).

Сенситивным возрастом для развития когнитивных характеристик, адекватной самооценки, критического мышления, адекватного восприятия социальных и культурных норм, навыков конструктивного общения со сверстниками, является именно младший школьный возраст. Психологи и педагоги разрабатывают программы занятий, направленные на формирование у дошкольников и школьников толерантного отношения к людям с инвалидностью. Занятия могут включать разные циклы бесед, встреч с людьми, имеющими инвалидность, может использоваться сказкотерапия, кинотерапия, мини-лекции, ролевые игры, работа в малых группах, чтение и обсуждение художественных произведений, тренинги для формирования готовности к взаимопомощи. Наибольшую популярность в современных российских школах сегодня имеют уроки доброты, цель которых - формирование позитивного отношения к нетипичным людям и объяснение, что инвалидность и особенности развития не могут быть основанием для социальной эксклюзии и дискриминации. На таких уроках обсуждаются темы стигматизации и дискриминации, вопросы социальной сегрегации или инклюзии, проблемы доступности образования, архитектурной среды для людей с ограниченными возможностями здоровья, социокультурные правила совместного бытия людей с разным уровнем психофизического развития (Пособие ... , 2012: 44). Для дошкольников на таких уроках с целью эмпатийного воспитания педагоги и психологи рекомендуют использовать такие произведения художественной литературы, как «Цветик-семицветик» (В. П. Катаев), «Аленький цветочек» (С. Т. Аксаков), «Карлик Нос» (В. Хауф), «Стойкий оловянный солдатик» (Г. Х. Андерсен) и др. Психологические особенности подросткового возраста ориентируют специалистов на иные приемы и методы (ролевые игры, квесты, анализ случаев, жизненных историй и биографий, просмотр и обсуждение кино-, документальных фильмов). В юности интенсивно формируется мировоззрение, готовность к личностному и профессиональному самоопределению, устойчивая и независимая Я-концепция, выстраивается система ценностей и формируются этические принципы и ориентиры собственного поведения. В работе со старшими школьниками для формирования культуры инклюзии можно использовать те же приемы, что и в работе с подростками, но важно учитывать субкультуру молодежных групп. Перспективными представляются волонтерские проекты, где появляется возможность в повседневных практиках и действиях знакомиться с людьми иными и не похожими на большинство. Залог успеха в деле формирования культуры 
инклюзии в комплексном применение разнообразных методик, способствующих воспитанию толерантности на всех этапах возрастного развития детей от детского сада до высшего образовательного учреждения.

Итак, на наш взгляд, инклюзивное образование сегодня можно считать одним из наиболее разработанных и успешных опытов, где формируется культура инклюзии. Формирование инклюзивной культуры становится частью социальной политики. Сегодня происходит дальнейшее развитие инклюзивных практик в системе образования, внимание уделяется не только инклюзивному обучению детей с ограниченными возможностями здоровья, принципы инклюзивной культуры начинают распространяться на детей мигрантов. Педагоги и психологи, погруженные в тематику инклюзивного обучения отмечают основные трудности связанные с несовершенством законодательной базы и невозможность полноценно пользоваться услугами системы здравоохранения и образования в случае с детьми из семей мигрантов и барьеры, связанные с непониманием и стигмой инвалидности, когда речь идет об инклюзивном обучении детей с нарушениями развития.

\section{СПИСОК ЛИТЕРАТУРЫ}

Бут, Т. (2007) Показатели инклюзии: практическое пособие / Т. Бут, М. Эйнскоу; под ред. М. Воган; пер. с англ. И. Аникеев; науч. ред. Н. Борисова, под общ. ред. М. Перфильевой. М.: РООИ «Перспектива». 124 с.

Колокольцева, М. А. (2012) Воспитание нравственных взаимоотношений у младших школьников в инклюзивном образовании : дисс. ... канд. пед. наук. Махачкала.

Наберушкина, Э. К. (2012) Инвалиды в большом городе: проблемы социального гражданства. М. : Вариант. 268с.

Пособие по проведению «Уроков доброты» со школьниками младших классов (2012) / авт.-сост. Е. Выговская, Ю. Симонова, Н. Хлудов и др. М.: Изд. РООИ «Перспектива». 44 с.

Сиротюк, А. С. (2014) Воспитание ребенка в инклюзивной среде. Методика, диагностика. М. : ТЦ Сфера. 128 с.

Хухлаева, О. В. (2011) Работа психолога в многонациональной школе: учебное пособие. М. : Форум. 176 с.

Creating an Inclusive Society: Practical Strategies to Promote Social Integration (2009) [Электронный ресурс] // Организация объединенных наций. URL: http:// www.un.org/esa/socdev/egms/docs/2009/Ghana/inclusive-society.pdf (дата обращения: 20.12.2017).

Дата поступления: 20.12.2017 2.

Полянский Андрей Иванович - доцент кафедры общей психологии и истории психологии Московского гуманитарного университета. Адрес: 111395, Россия, г. Москва, ул. Юности, д. 5. Тел.: +7 (499) 374-67-20. Эл. адрес: aipol-69@mail.ru

Мартиросян Варвара Давидовна - студент факультета психологии, педагогики и социологии Московского гуманитарного университета. Адрес: 111395, Россия, г. Москва, ул. Юности, д. 5. Тел.: +7 (499) 374-67-20. Эл. адрес: varya.martivosyan@ mail.ru 
Polyansky Andrey Ivanovich, Associate Professor, Department of General Psychology and the History of Psychology, Moscow University for the Humanities. Postal address: 5, Yunosti St., Moscow, Russian Federation, 111395. Tel.: + 7(499) 374-67-20. E-mail: aipol-69@mail.ru

Martirosyan Varvara Davidovna, Student, Faculty of Psychology, Pedagogy and Social Science, Moscow University for the Humanities. Postal address: 5, Yunosti St., Moscow, Russian Federation, 111395. Tel.: + 7(499) 374-67-20. E-mail: varya.martivosyan@mail.ru

\section{Для цитирования:}

Полянский А. И., Мартиросян В. Д. Инклюзивная культура в образовательной организации [Электронный ресурс] // Научные труды Московского гуманитарного университета. 2018. № 1. URL: http://journals.mosgu.ru/trudy/article/view/682 (дата обращения: дд.мм.гг.). DOI: 10.17805/trudy.2018.1.7 